\title{
Epidemiological and cost analysis of burn injuries admitted to the emergency department of a tertiary burn center
}

Tolga Eser ${ }^{1}$, Cemil Kavalci', Cem Aydogan² and Afsin Emre Kayipmaz ${ }^{1 *}$

\begin{abstract}
Background: Burn injury is an emergency medical condition that rapidly develops as a result of tissue exposure to electrical, chemical or thermal energy. Therefore, its treatment usually begins at the emergency department. In this study we aimed to perform an epidemiological analysis of burn injuries presenting to the emergency department of a tertiary burn center, and factors affecting the cost of their medical care.

Methods: Patients who presented to Baskent University Ankara Hospital Adult Emergency Department with burn injuries between January 2012 and December 2014 were studied for age, sex, time of admission, type of burn injury, clinical prognosis, mortality rate, percent burn area, and total cost of care. A total of 264 patients were enrolled. Chi square test was used for the comparison of categorical variables. Non-parametric tests were used for the comparison of continuous variables.

Results: This study included 179 (67.8\%) women and 85 (32.2\%) men. The most common types of burn injuries were hot water burns and scalding. Eleven point seven percent of the patients sustained burn injuries in occupational accidents. $95.1 \%$ of the patients were discharged from the emergency and $4.5 \%$ of them were hospitalized. Only 1 $(0.4 \%)$ patient died. There was no significant difference between patient outcomes (discharge vs. hospital admission) with respect to the cost of care $(p=0.846)$ No significant difference was found between the cost of care of surgical and non-surgical management of burn injuries $(p=0.206)$. No significant difference was found between the costs of care of different types of burn injuries $(p=0.053)$. There was a significant difference between burn degrees with respect to the cost of care $(p=0.038)$. A significant difference was found between the costs of care of patients with a percent burn area of less than $10 \%$ and those with a percent burn area of more than $10 \%(p<0.001)$, indicating that as percent burn area increased, a proportional increase occurred in the cost of care.
\end{abstract}

Conclusions: Burn degree and percent burn area were the main determinants of the cost of care of burn injuries. In conclusion, burn injuries are preventable by taking occupational measures and raising public awareness about domestic accidents.

Keywords: Burns, Cost analysis, Emergency treatment, Epidemiology

\section{Background}

Burn injury is an emergency medical condition that rapidly develops as a result of tissue exposure to electrical, chemical or thermal energy. Therefore, its treatment usually begins at the emergency department. Since a

\footnotetext{
*Correspondence: aekayipmaz@hotmail.com

1 Department of Emergency, Faculty of Medicine, Baskent University,

Fevzi Cakmak Street No: 45 Bahcelievler, Cankaya, Ankara, Turkey

Full list of author information is available at the end of the article
}

significant proportion of patients affected by burn injury are admitted to the emergency department immediately after the incident, healthcare staff working in the emergency department should have a good command of these cases (Alharbi et al. 2012). After providing first medical aid at the emergency department, it is imperative that multiple departments, particularly general surgery and plastic surgery, cooperate for the management of burn injuries (Ilhan et al. 2012). 
A major proportion of patients with burn injuries are discharged from the emergency department once outpatient treatment and follow-up is scheduled (Yolcu et al. 2013). When hospital admissions are taken into account, however, burn injuries are a significant source of mortality and morbidity (Sever et al. 2011). Furthermore, demanding medical care of these patients gives rise to the high cost of care depending on burn percentage, degree, as well as the duration of hospital stay (Hazar et al. 2013). Hence, taking preventive measures to avoid these injuries is the key to success for their management. Emergency physicians who assume a critical role in the management of burn injuries should necessarily have knowledge of the most common types of burn injuries and their cost of care in the emergency department.

In this study we aimed to perform an epidemiological analysis of burn injuries presenting to the emergency department of a tertiary burn center, and factors affecting the cost of their medical care.

\section{Methods}

This retrospective descriptive study was conducted after being approved by Baskent University Faculty of Medicine Ethics Committee (Project No: KA14/282 Date of Approval: 15.10.2014). Patients who presented to Baskent University Ankara Hospital Adult Emergency Department with burn injuries between January 2012 and December 2014 were studied for age, sex, time of admission, type of burn injury, clinical prognosis, mortality rate, percent burn area, and total cost of care. A total of 264 patients were enrolled.

Hospital automation system was used to access patients' medical data including age; sex; hour, month, and year of admission; cause and type of burn injury; occupational and suicidal nature of burn injury; burn degree; percent burn area; surgical intervention if performed; indications for admission according to the rule of nines; post-treatment clinical status, regular attendance to follow-up visits; and cost of care denominated in Euro $(€)$. The sum for treatment cost has been obtained by adding up the invoice amounts of the inpatients and all the check-ins to the emergency department and burns outpatient department.

International Classification of Diseases (ICD) diagnostic codes T30, T31, and T32 were used to determine and record burn injuries. Statistical analyses were done with "SPSS 17.0 for Windows" software package. Chisquare test was used for the comparison of categorical variables. The distribution of continuous variables was assessed with the Kolmogorov-Smirnov test. Non-parametric tests were used for the comparison of continuous variables.
The correlation between various variables and cost of care was analyzed with the Spearman's correlation test. A $p$ value of less than 0.05 was considered statistically significant.

\section{Results}

This study included 179 (67.8 \%) women and $85(32.2 \%)$ men. Thirty-four $(12.9 \%)$ patients were admitted to emergency department between 00:00 and 06:00; 15 (5.7 \%) between 06:00 and 12:00; 74 (28 \%) between 12:00 and 18:00; and 141 (53.4\%) between 18:00 and 24:00. The monthly distribution of the emergency department admissions for burn injuries was shown in Table 1 . Accordingly, patients suffering from burns check into emergency department most frequently between 18:00 and 24:00 and in June.

Seventy-seven $(29.2 \%)$ patients were admitted in 2012; $126(47.7 \%)$ in 2013; and 61 (23.1\%) in 2014. One hundred and ninety-five $(73.9 \%)$ patients were admitted for hot water burns-scalding; 25 (9.5 \%) for flame burns; 24 (9.1\%) for hot contact burns; 18 (6.8 \%) for chemical and $2(0.8 \%)$ for electric burns. The most common types of burn injuries were hot water burns and scalding. Thirtyone $(11.7 \%)$ patients sustained burn injuries in occupational accidents and 233 (88.3\%) in non-occupational accidents. There was no suicidal burn injury in our study. Two hundred and fifty-one $(95.1 \%)$ patients were discharged from the emergency department and $12(4.5 \%)$ were hospitalized. Only $1(0.4 \%)$ patient died. $70.8 \%$ of the patients involved $(n=187)$ are found to have attended to outpatient clinic controls, and $28.8 \%$ have not.

There was no significant difference between patient outcomes (discharge vs. hospital admission) with respect to the cost of care $(p=0.846)$ (Table 2).

Table 1 Monthly distribution of admissions for burn injuries

\begin{tabular}{lcc}
\hline Month & Number $(\boldsymbol{n})$ & Percentage (\%) \\
\hline January & 24 & 9.1 \\
February & 25 & 9.5 \\
March & 23 & 8.7 \\
April & 19 & 7.2 \\
May & 28 & 10.6 \\
June & 38 & 14.4 \\
July & 32 & 12.1 \\
August & 20 & 7.6 \\
September & 14 & 5.3 \\
October & 13 & 4.9 \\
November & 18 & 6.8 \\
December & 10 & 3.8 \\
Total & 264 & 100.0
\end{tabular}


Table 2 Comparison of cost of care by patient outcome

\begin{tabular}{lllll}
\hline Outcome & $\begin{array}{l}\text { Number of } \\
\text { patients }\end{array}$ & Median $(\boldsymbol{\epsilon})$ & IQR & $\boldsymbol{p}$ value \\
\hline Discharge & 251 & 25.14 & 21.84 & $0.846^{*}$ \\
Hospital admission & 12 & 26.10 & 31.58 & \\
\hline
\end{tabular}

IQR inter-quartile range

* Mann-Whitney-U test

It was found that there was no statistically significant difference between the gender-based groups $(p=0.079)$ (Table 3).

It was found that there was no statistically significant difference between the patients who were older versus younger than $50(p=0.593)$ (Table 4$)$.

There was a significant difference between the years of admission with respect to the cost of care $(p<0.001)$. Based on the annual analysis, the highest cost of care was incurred in 2012 and the lowest in 2014 (Table 5).

Table 3 Comparison of gender-based groups in terms of costs

\begin{tabular}{lllll}
\hline Gender & $\begin{array}{l}\text { Number of } \\
\text { patients }\end{array}$ & Median $(\boldsymbol{\epsilon})$ & IQR & $\boldsymbol{p}$ value \\
\hline Female & 179 & 24.22 & 19.26 & $0.079^{*}$ \\
Male & 85 & 27.77 & 28.96 & \\
\hline
\end{tabular}

IQR inter-quartile range

* Mann-Whitney- $U$ test

Table 4 Comparison of age-based groups in terms of costs

\begin{tabular}{lllll}
\hline Age & $\begin{array}{l}\text { Number of } \\
\text { patients }\end{array}$ & Median $(\boldsymbol{\epsilon})$ & IQR & $\boldsymbol{p}$ value \\
\hline$<50$ & 214 & 25.25 & 20.71 & 0.593 \\
$\geq 50$ & 50 & 26.16 & 26.99 & \\
\hline
\end{tabular}

Table 5 Comparison of the cost of burn care in different years of admission

\begin{tabular}{lclll}
\hline Year of admission & $\begin{array}{l}\text { Number of } \\
\text { patients }\end{array}$ & Median $(\boldsymbol{\epsilon})$ & IQR & $\boldsymbol{p}$ value \\
\hline 2012 & 77 & 30.29 & 27.50 & $<0.001^{*}$ \\
2013 & 126 & 26.24 & 20.44 & \\
2014 & 61 & 17.50 & 10.49 & \\
\hline
\end{tabular}

IQR inter-quartile range

* Kruskal-Wallis test

No significant difference was found between the cost of care of surgical and non-surgical management of burn injuries $(p=0.206)$ (Table 6).
No significant difference was found between the costs of care of different types of burn injuries $(p=0.053)$ (Table 7).

There was a significant difference between burn degrees with respect to the cost of care $(p=0.038)$. The second degree burns incurred the highest cost of care while the third degree burns led to the lowest cost of care (Table 8).

A significant difference was found between the costs of care of patients with a percent burn area of less than $10 \%$ and those with a percent burn area of more than $10 \%(p=0.001)$, indicating that as percent burn area increased, a proportional increase occurred in the cost of care (Table 9).

There was a significant positive correlation between age and treatment cost $(r=0.184, p=0.003)$, and also between percent burn area and treatment cost $(r=0.804$, $p<0.001$ ).

According to the descriptive statistics table, it was found that those who have 2.degree burns belong to the highest age group and those who have 3.degree burns belong to the lowest age group (Table 10).

According to the descriptive statistics table, the most frequent reason of burns for the older age group is flame burnt while the most frequent reason for young age groups is contacted with hot objects (Table 11).

Of the patients, those who were applied surgical intervention were older than those who were not applied surgical intervention (Table 12).

Hospitalized patients are of higher age group while those who were discharged from hospital were the lowest (Table 13).

\section{Discussion}

According to our study, there is no statistically significant difference between the patients' discharged from the hospital versus hospitalized statuses in terms of costs $(p=0.846)$. We consider that the reason for above concern is that the cost analysis figures were including the costs arising from patients' subsequent applications to burns outpatient department. Accordingly, we think that outpatient treatment versus inpatient treatment does not make a difference in terms of treatment costs. And despite the apparently higher costs of the patients who were applied surgical intervention; our statistical analysis has shown that there was no significant difference between the two groups $(p=0.206)$. Considering the variables such as the need for general anesthesia, the materials used, the necessity of multidisciplinary approach we expect the cost of the patients who are subject to surgical intervention, be higher. As a result of our study, we observed no significant difference between the cost versus the reason of the burns $(p=0.053)$. However, it is 
Table 6 Comparison of costs of care of surgical versus non-surgical management of burn injuries

\begin{tabular}{lcccccc}
\hline Surgical intervention & Number of patients & Median $(\boldsymbol{\epsilon})$ & IQR & Min & Max & $\boldsymbol{p}$ value \\
\hline Not performed & 258 & 25.09 & 21.61 & 5.96 & 190.93 & $0.206^{*}$ \\
Performed & 6 & 48.29 & 254.23 & 9.60 & 475.52 & \\
\hline
\end{tabular}

$I Q R$ inter-quartile range, min minimum, max maximum

* Mann-Whitney- $U$ test

Table 7 Comparison of the costs of care of different types of burn injury

\begin{tabular}{lllll}
\hline $\begin{array}{l}\text { Cause of burn } \\
\text { injury }\end{array}$ & $\begin{array}{l}\text { Number } \\
\text { of patients }\end{array}$ & Median $(\boldsymbol{\epsilon})$ & IQR & $\boldsymbol{p}$ value \\
\hline Hot water-scalding & 195 & 25.96 & 21.27 & $0.053^{*}$ \\
Flame & 25 & 29.05 & 73.05 & \\
Contact with hot & 24 & 18.37 & 13.43 & \\
Chemical & 18 & 18.60 & 24.92 & \\
Electric & 2 & 23.74 & - & \\
\hline
\end{tabular}

$I Q R$ inter-quartile range

* Kruskal-Wallis test

Table 8 Comparison of treatment costs by burn degree

\begin{tabular}{lcccc}
\hline Burn degree & $\begin{array}{l}\text { Number of } \\
\text { patients }\end{array}$ & Median $(\boldsymbol{\epsilon})$ & IQR & $\boldsymbol{p}$ value \\
\hline 1. Degree & 49 & 23.29 & 16.21 & $0.038^{*}$ \\
2. Degree & 208 & 26.24 & 24.28 & \\
3. Degree & 7 & 14.70 & 4.63 & \\
\hline
\end{tabular}

* Kruskal-Wallis test

$I Q R$ inter-quartile range

Table 9 Comparison of cost of care by percent burn area

\begin{tabular}{lllll}
\hline $\begin{array}{l}\text { Percent burn } \\
\text { area }\end{array}$ & $\begin{array}{l}\text { Number } \\
\text { of patients }\end{array}$ & Median $(\boldsymbol{\epsilon})$ & IQR & $\boldsymbol{p}$ value \\
\hline $\begin{array}{l}\text { Percent burn } \\
\text { area }<\% 10\end{array}$ & 250 & 24.93 & 20.17 & $<0.001^{*}$ \\
$\begin{array}{l}\text { Percent burn } \\
\text { area } \geq \% 10\end{array}$ & 14 & 75.00 & 75.54 & \\
\hline
\end{tabular}

$I Q R$ inter-quartile range

* Mann-Whitney- $U$ test

Table 10 Age of the patients versus burn degree

\begin{tabular}{lll}
\hline & Median (year) & IQR \\
\hline 1. Degree & 29.00 & 19.00 \\
2. Degree & 35.00 & 23.00 \\
3. Degree & 30.00 & 11.00 \\
\hline
\end{tabular}

Table 11 Patient age versus reason of burns

\begin{tabular}{llc}
\hline Cause of burn injury & Median (year) & IQR \\
\hline Hot water-scalding & 32.00 & 22.00 \\
Flame & 37.00 & 21.00 \\
Contact with hot & 26.50 & 25.00 \\
Chemical & 31.00 & 13.00 \\
Electric & 31.50 & - \\
\hline
\end{tabular}

Table 12 Patient age versus surgical intervention

\begin{tabular}{lll}
\hline Surgical intervention & Median (year) & IQR \\
\hline Not performed & 32.50 & 21.00 \\
Performed & 38.00 & 38.00 \\
\hline
\end{tabular}

Table 13 Age of patient versus clinical outcome

\begin{tabular}{lll}
\hline & Median (year) & IQR \\
\hline Discharge & 32.00 & 21.00 \\
Hospital admission & 37.00 & 28.00 \\
\hline
\end{tabular}

observed that the burns which occur due to flame exposure result in remarkably higher costs. No statistically significant data has been observed between patient age versus cost $(p=0.593)$. There is a statistically significant difference between the degree of the burn versus cost (respectively $p<0.001$ and $p=0.038$ ). This means that the cost is determined by the burnt area and its degree rather than the patient's age.

Our study revealed that, among burn survivors admitted to our emergency department, female burn survivors were 2.1 times more common than male burn survivors. This was in contrast to a study by Saritas et al. (2011), which reported that $65 \%$ of burn survivors who were admitted to the emergency department were male. We believe that more female survivors were admitted in our series due to the proximity of our hospital to residential areas and small-sized workplaces and its remoteness to industrial areas. 
The median age of our study population was 33 years. Kowal-Vern et al. (2014) similarly reported a median age of 30 years for burn injury survivors. We think that the reason for young adults suffering from burns is observed more frequently is because these individuals are more active at home and at work. Young adults are more open to traumas and therefore the burns due to their motorvehicle use, alcohol consumption and that they can work under heavy-duty labor requirements.

The most frequent time period for admissions was between 18:00 and 00:00 (54.4\%). DeKoning et al. (2009) also reported that admissions for burn injuries most commonly took place between 18:00 and 19:00. We considered that spending more time in low-safety, uncontrolled places and at kitchen during this period caused an increase in the burn injuries.

In our study, the most common types of burn injury were, in descending order of frequency, hot water burnsscalding, flame burns, and burns by contact with hot substances/surfaces. This finding was in agreement with that reported by Kowal-Vern et al. (2014). However, Avsarogullari et al. (2003) and Ahn and Maitz (2012) reported that flame burns were the most common types of burn injury followed by scalding. The study of Avsarogullari et al. (2003), as it can be seen in our study, consists of burn patients who check into the emergency department. As for Ahn and Maitz's (2012) study, it did not consist of emergency service patients but inpatients of the burns unit. This can be one of the authentic properties of our study among other studies within the literature. Our finding may be a reflection of our hospital's proximity to residential areas and small-sized workplaces.

As the majority of our cases were minor burn injuries, the median percent burn area was only $2 \%$. In the literature, percent burn area has been variably reported (Kowal-Vern et al. 2014; Avsarogullari et al. 2003; Aksoy et al. 2014; Sahin et al. 2011). This suggests that in our patients burn injuries may have occurred in different ways at home, workplace, or many other different settings, and thus the range of burn degrees may have been diverse.

Our study demonstrated that second-degree burns were the most common burn degree $(78.78 \%)$, a finding that was similarly reported by many other studies (DeKoning et al. 2009; Avsarogullari et al. 2003; Burton et al. 2009). Although it may show variability by different causes of burn injury, it is possible that the seconddegree burn injuries were more common in patients with flame or scalding burn injuries.

According to our results, $11.7 \%$ of burn injuries occurred in occupational accidents. Karami Matin et al.
(2012) reported that occupational burn injuries constituted $28.5 \%$ of their cases. This finding suggests that recent national measures taken for occupational health and safety have raised workers' awareness about burn injuries and transformed workplaces to safer environments.

In our study we found that surgical treatment was used in $2.3 \%$ patients with burn injuries. This low number possibly resulted from the mildness of burn injuries in our patients.

Similar to what Sahin et al. (2011) reported, we found that cost of care was not significantly different between various causes of burn injuries. We determined that flame burns were associated with higher cost of care, as Karami Matin et al. (2012) reported.

The cost of care of burn injuries with a percent burn area of less than $10 \%$ was lower than that of burn injuries occupying more than $10 \%$ of body surface area. This suggests that cost of care is affected by percent burn area. Ahn and Maitz (2012) also demonstrated that an increase in percent burn area was the primary factor leading to a proportional increase in cost of care. In patients with a greater percent burn area, hospitalization may be prolonged and complications may develop. Furthermore, increased use of workforce and medical materials lead to increased cost of care (Ahn and Maitz 2012).

We found a significant difference between burn degrees with regard to the cost of care. Burn degree and depth are similarly known to affect patient prognosis. In our study, the cost of care of second-degree burns was greater than third degree burns. Follow-up appointments of second-degree burn injuries are recommended to be spaced more closely to avoid complications. This probably led to a higher cost by increasing the number of procedures performed and medical equipment used at each visit, increasing overall cost in our study. We failed to detect any significant difference between the cost of care of patients managed surgically versus non-surgically $(p=0.206)$. Jansen et al. (2012), however, reported that early surgery allowed cost saving by decreasing the duration of hospital stay.

\section{Conclusions}

The proximity to our hospital to residential areas and small-sized workplaces led to a greater percentage of hot water-scalding injuries that presented to our emergency department. Burn degree and percent burn area were the main determinants of the cost of care of burn injuries. In conclusion, burn injuries are preventable by taking occupational measures and raising public awareness about domestic accidents. 


\section{Authors' contributions}

TA, CK, and AEK conceived of the study, collected the data and participated in its design and coordination and drafted the manuscript. CA participated in the design of the study and helped to perform the statistical analysis. All authors read and approved the final manuscript.

\section{Author details}

${ }^{1}$ Department of Emergency, Faculty of Medicine, Baskent University, Fevzi Cakmak Street No: 45 Bahcelievler, Cankaya, Ankara, Turkey. ${ }^{2}$ Department of General Surgery, Faculty of Medicine, Baskent University, Ankara, Turkey.

\section{Competing interests}

The authors declare that they have no competing interests.

Received: 7 June 2016 Accepted: 19 August 2016

Published online: 24 August 2016

\section{References}

Ahn CS, Maitz PK (2012) The true cost of burn. Burns 38:967-974

Aksoy N, Arli S, Yigit O (2014) A retrospective analysis of the burn injury patients records in the emergency department, an epidemiologic study. Emerg (Tehran) 2:115-120

Alharbi Z, Piatkowski A, Dembinski R, Reckort S, Grieb G, Kauczok J, Pallua N (2012) Treatment of burns in the first 24 hours: simple and practical guide by answering 10 questions in a step-by-step form. World J Emerg Surg 7:13

Avsarogullari L, Sozuer E, Ikizceli I, Kekec Z, Yurumez Y, Ozkan S (2003) Adult burn injuries in an emergency department in Central Anatolia, Turkey: a 5-year analysis. Burns 29:571-577
Burton KR, Sharma VK, Harrop R, Lindsay R (2009) A population-based study of the epidemiology of acute adult burn injuries in the Calgary Health Region and factors associated with mortality and hospital length of stay from 1995 to 2004. Burns 35:572-579

DeKoning EP, Hakenewerth A, Platts-Mills TF, Tintinalli JE (2009) Epidemiology of burn injuries presenting to North Carolina emergency departments in 2006-2007. Burns 35:776-782

Hazar E, Ince AR, Cam S, Karagoz N (2013) Cost analysis of service businesses: the cost analysis of hospitalized patients in Numune Hospital burn unit of Sivas. BMSIJ 1:156-167

Ilhan E, Dal O, Yakan S, Cengiz F (2012) Evaluation of the burn patients presenting to emergency clinic of an education hospital. J Clin Anal Med $3: 268-270$

Jansen LA, Hynes SL, Macadam SA, Papp A (2012) Reduced length of stay in hospital for burn patients following a change in practice guidelines: financial implications. J Burn Care Res 33:e275-e279

Karami Matin B, Karami Matin R, Ahmadi Joybari T, Ghahvehei N, Haghi M, Ahmadi M, Rezaei S (2012) Epidemiological data, outcome, and costs of burn patients in Kermanshah. Ann Burns Fire Disasters 25:171-177

Kowal-Vern A, Bokhari F, Poulakidas S (2014) Demographic comparison of burn emergency only visits and admissions in an urban burn center. J Burn Care Res. doi:10.1097/BCR.0000000000000197

Sahin I, Ozturk S, Alhan D, Acikel C, Isik S (2011) Cost analysis of acute burn patients treated in a burn centre: the Gulhane experience. Ann Burns Fire Disasters 24:9-13

Saritas A, Cikman M, Candar M, Kandis H, Baltaci D (2011) Retrospective analysis of judicial burn cases admitted to our clinic: 4-year experience. Duzce Med J 13:29-33

Sever C, Kulahci Y, Duman H (2011) Prediction of mortality and causes of death in a burn centre: a retrospective clinical study. J Clin Anal Med 2:24-26

Yolcu S, Beceren NG, Timucin H, Uludag U (2013) Emergency service admissions of patients with burn injury. J Clin Exp Investig 4:285-288

\section{Submit your manuscript to a SpringerOpen ${ }^{\circ}$ journal and benefit from:}

- Convenient online submission

- Rigorous peer review

- Immediate publication on acceptance

- Open access: articles freely available online

- High visibility within the field

- Retaining the copyright to your article

Submit your next manuscript at springeropen.com 